\title{
Cenarização prospectiva do acesso à água no semiárido paraibano: entrelaçamentos e desafios
}

\author{
Prospective scenarization of access to water in the semi-arid paraiban: links and challenges \\ Cenarización prospectiva del acceso el agua em el semiárido paraibano: entrelazamientos y desafíos
}

Recebido: 28/01/2022 | Revisado: 05/02/2022 | Aceito: 11/02/2022 | Publicado: 16/02/2022

\author{
Maria Aparecida de Souza \\ ORCID: https://orcid.org/0000-0002-8193-0706 \\ Universidade Federal de Campina Grande, Brasil \\ E-mail: apre-cida@hotmail.com \\ Ângela Maria Cavalcanti Ramalho \\ ORCID: https://orcid.org/0000-0002-8567-4367 \\ Universidade Estadual da Paraíba, Brasil \\ E-mail: angelamcramalho@gmail.com
}

\begin{abstract}
Resumo
O estudo tem como objetivo construir cenários prospectivos sobre o acesso à água pela população rural no município de Cubati-PB, Seridó Oriental Paraibano. A limitação de acesso à água no semiárido nordestino, em face à situação da população historicamente afetada pela seca em áreas ambientalmente vulneráveis, produz efeitos sociais, ambientais e econômicos agravantes, em especial no meio rural, que refletem nas desigualdades significativas que há dentro da região, como dificuldade de acesso à água potável em uma quantidade mínima aceitável para uso humano. A metodologia da pesquisa utilizada foi a aplicação parcial do método proposto por Marcial e Grumbach (2000). A coleta de dados foi realizada através de observação in loco, conversas informais, registros fotográficos e aplicação de entrevistas semiestruturadas para escolha das variáveis preliminares com impacto no acesso à agua nos últimos dez anos e aplicação de questionários por meio do Google Forms para escolha dos eventos definitivos que irão impactar o sistema estudado nos próximos cinco anos. Também foi utilizado o preenchimento da matriz de impactos cruzados e escolha das variáveis que ocorrem em cada um dos cenários: mais provável, de tendência e ideal. Conclui-se que o desafio no processo de democratização do acesso à água no atendimento das famílias de baixa renda nas comunidades rurais do semiárido nordestino demanda descentralização do abastecimento da água, adequada gestão do uso da água nos períodos de estiagem e planejamento hídrico com a participação de diversos atores sociais para garantir o acesso prioritário e os usos múltiplos desse recurso natural.
\end{abstract}

Palavras-chave: Cenários prospectivos; Água; Gestão hídrica.

\begin{abstract}
The study aims to build prospective scenarios on access to water by the rural population in the municipality of CubatiPB, Seridó Oriental Paraibano. The limited access to water in the northeastern semi-arid region, given the situation of the population historically affected by drought in environmentally vulnerable areas, produces aggravating social, environmental and economic effects, especially in rural areas, which are reflected in the significant inequalities that exist within the region, such as difficulty in accessing potable water in a minimum quantity acceptable for human use. The research methodology used was the partial application of the method proposed by Marcial and Grumbach (2000). Data collection was carried out through on-site observation, informal conversations, photographic records and application of semi-structured interviews to choose the preliminary variables with an impact on access to water in the last ten years and application of questionnaires through Google Forms to choose the events that will impact the system studied in the next five years. It was also used to fill in the cross-impact matrix and choose the variables that occur in each of the scenarios: most likely, trend and ideal. It is concluded that the challenge in the process of democratizing access to water in the service of low-income families in rural communities in the northeastern semi-arid region demands decentralization of water supply, adequate management of water use in periods of drought and water planning with the participation of different social actors to guarantee priority access and multiple uses of this natural resource.
\end{abstract}

Keywords: Prospective scenarios; Water; Water management.

\section{Resumen}

El estudio tiene como objetivo construir escenarios prospectivos sobre el acceso al agua por la población rural en el municipio de Cubati-PB, Seridó Oriental Paraibano. La limitación del acceso el agua en el semiárido nordestino, ante la situación de la población históricamente afectada por la sequía en áreas ambientalmente vulnerables, produce efectos sociales, ambientales y económicos agravantes, en especial en el medio rural, que se reflejan en las 
desigualdades significativas que existen dentro de la región, como dificultad de acceso el agua potable en una cantidad mínima aceptable para uso humano. La metodología de la investigación utilizada fue la aplicación parcial del método propuesto por Marcial y Grumbach (2000). La recolección de datos se llevó a cabo mediante observación in situ, conversaciones informales, registros fotográficos y aplicación de entrevistas semiestructuradas para elegir las variables preliminares con impacto en el acceso el agua en los últimos diez años y aplicación de cuestionarios por medio de Google Forms para elegir los eventos definitivos que irán impactar el sistema estudiado en los próximos cinco años. También se utilizó el relleno de la matriz de impactos cruzados y elección de las variables que ocurren en cada uno de los escenarios: más probable, de tendencia e ideal. Se concluye que el desafío en el proceso de democratización del acceso el agua en la atención de las familias de bajos ingresos en las comunidades rurales del semiárido nordestino demanda descentralización del abastecimiento de agua, adecuada gestión del uso del agua en los períodos de sequía y planificación hídrico con la participación de diversos actores sociales para garantizar el acceso prioritario y los usos múltiples de ese recurso natural.

Palabras clave: Escenarios prospectivos; Agua; Gestión hídrica.

\section{Introdução}

O cenário do semiárido nordestino apresenta mudanças climáticas que afetam a disponibilidade de água com altas temperaturas durante o ano todo, baixas amplitudes térmicas, forte insolação e altas taxas de evapotranspiração. As taxas de evapotranspiração elevadas superam os índices pluviométricos, ocasionando taxas negativas no balanço hídrico (ANA, 2015).

As limitações de acesso à água no semiárido nordestino, em face, à situação da população historicamente afetada pela seca, em áreas ambientalmente vulneráveis, produz efeitos sociais, ambientais e econômicos agravantes em especial para a população em situação de vulnerabilidade social no meio rural, uma vez que concentra uma elevada proporção da população. Esse percentual esconde as desigualdades significativas que há dentro da região, com baixos índices de desenvolvimento humano e dificuldades de acesso à água potável em uma quantidade mínima aceitável para uso humano.

Os dados do Censo Demográfico de 2010 (IBGE, 2010), demonstram que cerca de 16 milhões de pessoas vivem em extrema pobreza no Brasil, considerando famílias com renda percapta de até $\mathrm{R} \$ 70,00$. Destes, quase $20 \%$ reside na zona rural do semiárido brasileiro, representando mais de 3 milhões de pessoas. A pobreza rural nessa região geralmente é associada à má distribuição dos recursos hídricos.

Por outro lado, evidencia-se que o contexto histórico hídrico da Região Nordeste tem sido marcado por políticas emergenciais e ações assistencialistas com ênfase na construção de açudes somadas à distribuição de alimentos. Agregado a essa problemática encontra-se o autoritarismo estatal na definição das alternativas a serem implementadas no combate à seca e à apropriação privada de investimentos públicos por oligarquias. Essas ações geram a concentração de poder econômico e político pelo controle do acesso à água e à terra, contribuindo para que ocorra um verdadeiro comércio de interesses por meio da problematização das secas (Assis, 2012).

Diante desses cenários, algumas ações mais contemporâneas foram implementadas a exemplo das políticas de tecnologias sociais para armazenamento de água, protagonizadas pela sociedade civil que ganharam destaque e impulsionaram mudanças de paradigmas na forma de enfrentamentos à seca no Semiárido, trazendo, com isso, muitos benefícios concretos também para a geração de renda.

Desse modo, o paradigma de combate à seca que orientou as políticas públicas de enfrentamento a esse problema especifico da região Nordeste, passou a ser confrontado com o paradigma de convivência com o Semiárido. Silva (2003) externa que, no tocante a necessidade e a possibilidade de convivência com os ecossistemas frágeis, a construção da sustentabilidade depende de um processo participativo da população local no resgate e construção cultural de alternativas apropriadas aos ecossistemas.

Portanto, o desafio no processo de democratização do acesso à água no atendimento das famílias de baixa renda nas comunidades rurais do semiárido nordestino demanda descentralização do abastecimento da água, adequada gestão do uso da 
água nos períodos de estiagem e planejamento hídrico com a participação de diversos atores sociais para garantir o acesso prioritário e os usos múltiplos desse recurso natural no recorte geográfico em estudo.

Diante do exposto, este trabalho tem como objetivo construir cenários prospectivos sobre o acesso à água pela população rural no município de Cubati, cidade situada no Seridó Oriental Paraibano.

\section{Referencial Teórico}

\subsection{A interlocução dos Paradigmas: Combate à seca e Convivência com a seca}

Historicamente o Semiárido brasileiro se apresenta como uma região socioambiental vulnerável em termos de acesso equitativo de água potável, o que amplia as assimetrias sociais de diversos grupos sociais excluídos e discriminados e demanda a adoção de políticas públicas, melhoria na gestão hídrica e planejamento governamental para uma melhor convivência da população com as escassez da água nas áreas vulneráveis. Também o acesso aos serviços de abastecimento de água e saneamento básico tão essencial para diminuir as desigualdades sociais e econômicas.

De acordo com Passador et al. (2010), a intervenção do Estado Brasileiro na região Nordeste sempre foi marcada pela centralização e fragmentação de suas ações e políticas públicas, se concretizando pela criação de organismos de "luta" contra a seca. Conforme Boff (2010, p. 49), "se não incorporarmos a inteligência emocional à razão instrumental-analítica, nunca vamos sentir os gritos dos famintos, o gemido da Mãe Terra, a dor das florestas abatidas e a devastação atual da biodiversidade". Para Silva (2006) "o desafio fundamental a ser dado às novas orientações de desenvolvimento sustentável no Semiárido é o de construir o sentido da convivência". O autor supracitado delineia cinco dimensões fundamentais que configuram o sentido de convivência, as quais se encontram no Quadro 1.

Quadro 1: Dimensões fundamentais que configuram o sentido de convivência.

\begin{tabular}{|c|c|}
\hline DIMENSÕES & DESCRIÇÃO \\
\hline Convivência com o meio ambiente & $\begin{array}{l}\text { Ocorrerá mediante o manejo e uso sustentáveis dos recursos naturais } \\
\text { num ecossistema. }\end{array}$ \\
\hline Economia da convivência & $\begin{array}{c}\text { Deverá estar pautada na combinação dos princípios e valores da } \\
\text { convivência com a viabilização das atividades econômicas necessárias } \\
\text { ao desenvolvimento sustentável. }\end{array}$ \\
\hline Convivência com qualidade de vida & $\begin{array}{l}\text { Está expressa na possibilidade de se viver bem com os outros seres em } \\
\text { um lugar. }\end{array}$ \\
\hline Cultura da convivência & $\begin{array}{c}\text { Requer a valorização e a reconstrução dos saberes da população local } \\
\text { sobre o meio em que vive, suas especificidades, fragilidades e } \\
\text { potencialidades. }\end{array}$ \\
\hline Política & $\begin{array}{c}\text { A convivência emerge e se configura como uma proposta política de } \\
\text { mobilização da sociedade e do Estado brasileiro para a implementação } \\
\text { de políticas públicas apropriadas ao desenvolvimento sustentável na } \\
\text { região semiárida. }\end{array}$ \\
\hline
\end{tabular}

Fonte: Elaborado pela autora com base em dados de Silva (2006).

Buriti e Barbosa (2019) defendem que os desafios à democratização da gestão da água no Brasil, previstos na atual Política Nacional de Águas, deverão passar pelo fortalecimento de iniciativas de apropriação cultural da ciência e tecnologia por parte da população e de planejamento participativo das políticas de convivência com a seca. O exame do processo histórico de institucionalização das políticas evidencia que esse pode ser o caminho necessário para torná-las mais efetivas e condizentes com a realidade cultural da população, visando garantir o direito fundamental do acesso à água para todas as pessoas.

Conti e Pontel (2013) retratam que a transição paradigmática na forma de enfrentamento à seca na região Semiárida, a qual é fundamentada na racionalidade da convivência e em um desenvolvimento com qualidade de vida, requerem a 
combinação de um conjunto de ações sociais, econômicas, culturais e políticas, articuladas com a disseminação e a afirmação de valores e práticas de igualdade e respeito à dignidade de cada ser humano e dos demais seres vivos.

Os autores supracitados remetem a abordagem sobre a transição paradigmática como sendo uma forma de lançar luzes que possibilitem ampliar os olhares e a compreensão do novo que emerge nas duas últimas décadas na região semiárida, a partir das dinâmicas organizativas e sociais que configuram novas formas de conceber e desenvolver ações em torno da água, da terra, da produção, da educação e de outras demandas que se expressam como a afirmação de uma 'ideia-projeto' e dá um novo sentido à convivência com o Semiárido configurando traços identitários do povo em seu território.

Desse modo, as percepções e ações que emergem das lacunas existente na busca de quebra de paradigmas em prol de um desenvolvimento sustentável para a região Semiárida sinalizam para um desafio junto aos formuladores de políticas públicas e aos movimentos sociais.

Nas últimas décadas, porém, com a intervenção de diversos atores, governamentais e não governamentais, vem sendo gerada outra concepção de ver, trabalhar e construir o Semiárido, baseada na compreensão de que: seu povo é cidadão; seca não se combate; é possível conviver com a semiaridez; a região é viável; uma sociedade justa se constrói baseada em equidade de gênero, tendo as mulheres como protagonistas de seus destinos; é essencial o desenvolvimento de um processo de educação para a convivência com o Semiárido que valorize o conhecimento construído pelo seu povo. Nasce, assim, a perspectiva da “convivência com o Semiárido" (Baptista \& Campos, 2013).

O pensamento tradicional que se refere à seca na região Semiárida como sendo algo a ser combatido deixa de ganhar espaço mediante o pensamento do novo paradigma de convivência com o Semiárido. De acordo com Baptista e Campos (2013) muito do que se produz e que a natureza disponibiliza nessa região não é suficientemente aproveitado por falta de uma cultura que crie condições de se guardar o produzido na época abundante para utilizá-lo em tempos de maiores necessidades e, assim, garantir a vida e a segurança alimentar. Enfoque relevante que será abordado a seguir no tocante às tecnologias sociais de acesso à água na zona rural do município de Cubati-PB.

\section{Material e Métodos}

O procedimento metodológico adotado em função do objetivo do estudo foi uma pesquisa exploratório-descritiva com abordagem analítica dos dados quantitativos. Para a coleta de dados quantitativos foram utilizados questionários para aplicação da metodologia de cenários, esta adaptada de Marcial e Grumbach (2006). O processo de aplicação dos questionários para a construção dos cenários ocorreu em três etapas: a primeira foi para redução dos eventos identificados no sistema como impactantes nos últimos 10 anos; a segunda foi uma aplicação do método de impactos cruzados proposto por Marcial e Grumbach (2006), utilizado para avaliar o grau de motricidade e dependência de cada variável em relação às outras; a terceira se deu mediante a opinião dos peritos em relação à presença ou ausência das variáveis em cada cenário.

Os peritos (conhecedores da realidade hídrica do município) que responderam os questionários referentes aos dados quantitativos constituem-se em: seis líderes de associações rurais, o Secretário de agricultura do município e o técnico da EMPAER (Empresa Paraibana de Pesquisa, Extensão Rural e Regularização Fundiária). O horizonte temporal dos cenários prospectivos foi de cinco anos, uma vez que foram considerados no sistema os impactos dos últimos 10 anos.

\subsection{Metodologia de Construção de Cenários Prospectivos}

A literatura apresenta uma abordagem diversificada para a construção de cenários prospectivos. Para construir esses cenários, é necessária uma metodologia passível de precisão e que possibilite a pontuação dos atores e das variáveis mais relevantes do sistema que se deseja cenarizar (Lessa et al, 2006). Na perspectiva de conhecer um pouco das principais metodologias de cenários a seguir será explanada a percepção de alguns autores. 
Conforme Marcial e Costa (2001), quatro métodos enquadram-se nas definições da prospectiva: o descrito por Godet (2000), o descrito por Schwartz (2006), também conhecido como Global Business Network (GBN), o descrito por Porter (1989) e o descrito por Marcial e Grumbach (2006). Tais métodos possuem uma série de características comuns, quais sejam: a) iniciam com a delimitação do problema que será cenarizado. Godet e Grumbach fazem essa delimitação ao definirem o sistema, Schwartz e Porter delimitam na dimensão da estratégia; b) realizam estudos históricos e descrição da situação atual; e c) consultam especialistas e/ou peritos, que são as pessoas conhecedoras do sistema.

Cenário na definição de Godet (2000) é o conjunto formado pela descrição coerente de uma situação futura e pelo encaminhamento dos acontecimentos que permitem passar da situação de origem à situação futura. Os cenários apresentam como foco, assuntos e informações relevantes para os tomadores de decisão, assim como os elementos previsíveis e imprevisíveis do ambiente que afetam o sistema em que o subsistema está inserido.

Marcial e Grumbach (2006) comentam que a Global Business Network (GBN) é uma empresa norte-americana voltada para formulação de cenários, criada em 1988, por Peter Schwartz. De acordo com Schwartz (2006), as etapas do Método são: identificar a questão ou decisão central; forças-chave no ambiente local; forças-motrizes - listar 48 forças principais que influenciam os fatores-chave; hierarquizar por importância e incerteza; selecionar e definir a lógica dos cenários e dos vetores em torno dos quais haverá mudança; incorporar os cenários; implicações: indicar as consequências dessa análise para a questão ou decisão central; selecionar os indicadores iniciais.

Na concepção de Porter (1989), cenários representam uma visão internamente consistente do futuro que poderá se efetivar. Trata-se de ferramentas que têm como objetivo melhorar o processo decisório com base em um possível futuro. Sua finalidade específica consiste em possibilitar a compreensão das diversas ameaças que o objeto de estudo poderá enfrentar em dado horizonte temporal e ajudar a elaborar uma visão de longo prazo. Marcial e Grubach (2006) discorrem que a prospecção de um cenário completo comumente contempla seis características principais, quais sejam: um título, uma filosofia, variáveis, atores, cenas e trajetórias. Os autores supramencionados pontuam que o método deve ser dividido em quatro fases, conforme exposto na (Figura 1).

O método Grumbach, escolhido para sistematizar a cenarização de acesso à água, se deu em decorrência dos avanços que o mesmo apresenta. Grumbach (2006) estudou o desenvolvimento de Cenários Prospectivos (CP) e desenvolveu uma metodologia alinhando ideias de autores consagrados às suas próprias conclusões e às de sua equipe.

Figura 1: Metodologia de Cenário Descrita por Marcial e Grumbach (2006).

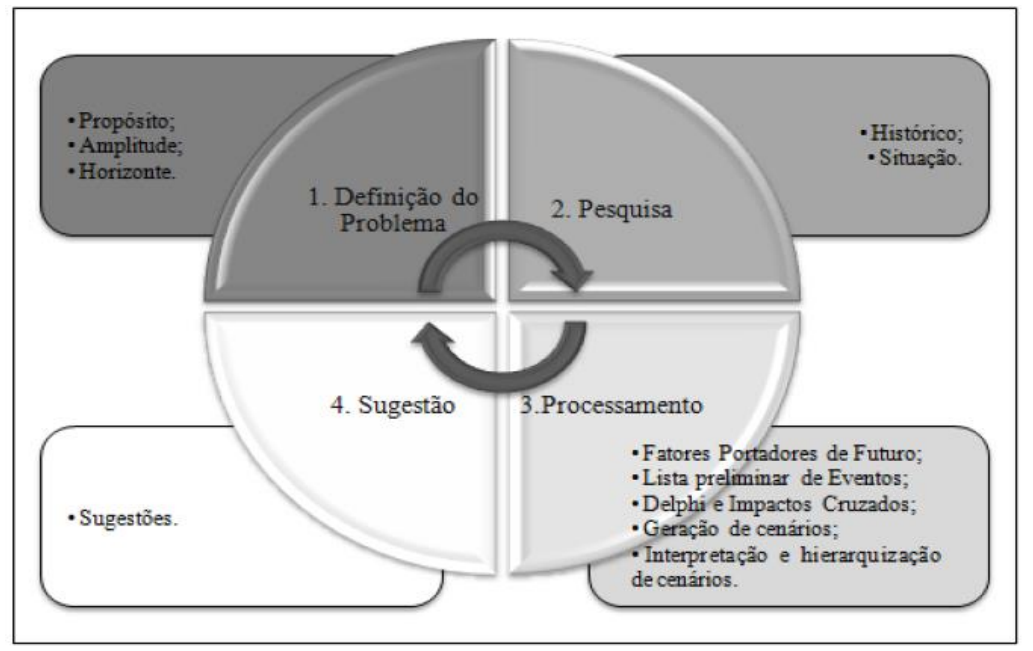

Fonte: Silva (2012). 


\subsection{Recorte Geográfico}

O Seridó Oriental Paraibano é formado por nove municípios, dentre eles, Cubati, o qual se caracteriza como sendo de pequeno porte demográfico. A área territorial do município corresponde a 163, $227 \mathrm{~km}^{2}$ e sua população é de 6.886 habitantes, dos quais, 4.769 residem no perímetro urbano e 2.097 na zona rural do município. O Índice de Desenvolvimento Humano é de 0,56 e ocupa a posição $162^{\mathrm{a}}$ dos 223 municípios paraibanos (IBGE, 2010). Quanto aos aspectos econômicos o PIB do município é de 41. 144, 000 ocupando a posição de $111^{\circ}$ em relação aos demais municípios paraibanos. O PIB Per capita corresponde a R\$5. 929, 34 (IBGE, 2012).

Por se tratar de uma microrregião inserida no semiárido as precipitações pluviométricas anuais são inferiores a 800 milímetros e o índice de aridez se configura em 0,5 , além de apresentar o risco de seca constante maior que $60 \%$, tendo por base o período de 1970 a 1999 (BRASIL, 2005). Somada a essas características, encontram-se as altas temperaturas, baixas amplitudes térmicas, forte insolação e altas taxas de evapotranspiração. De acordo com a ANA (Agência Nacional de Águas, 2015), as taxas de evapotranspiração superam os índices pluviométricos, ocasionando taxas negativas no balanço hídrico. Essas características configuram à região, longos períodos de estiagem.

O Bioma presente na área de estudo é a Caatinga com predominância de vegetação adaptada ao clima semiárido. Os solos são pedregosos e rasos, onde muitas vezes tornam-se visíveis os afloramentos de corpos cristalinos. A zona urbana do município em estudo é abastecida pela Companhia de Água e Esgoto do Estado da Paraíba (CAGEPA), com água proveniente do manancial Epitácio Pessoa. Já a zona rural possui fontes de abastecimentos difusas, a qual serão cenarizadas no presente estudo.

\section{Resultados e discussões}

\subsection{Acesso à água na zona rural de Cubati-PB}

O acesso à água é um direito humano fundamental que precisa ser garantido a toda população. Contudo, embora esse direito seja reconhecido em vários documentos oficiais, muitas pessoas não têm o direito assegurado para o consumo humano e outras atividades. No caso do Semiárido Brasileiro, muitos estudiosos apontam que o problema não é a falta de água das chuvas e nem de estruturas de acondicionamento, mas sim, a destinação das águas dos mananciais para as cidades e a concentração nas mãos de poucos na zona rural.

Para que essa situação seja revertida, serão necessárias estruturas de acondicionamentos e a adoção da cultura do partilhamento, de modo a atender toda população de forma equitativa. Assim, a sistematização de um cenário de acesso à água na zona rural do município de Cubati-PB, vai enfatizar todas as possibilidades de acesso à água.

No município estudado foi diagnosticado a presença de reservatórios de água implementados no modelo tradicional, tais como: açudes de médio porte construídos tanto pelo poder público, como em terras particulares pelos proprietários dessas terras, fato que ocasiona a concentração das águas nas mãos de poucos. Também foram diagnosticadas várias ações pautadas no novo paradigma, ou seja, o de convivência com o Semiárido. Essas ações se concretizaram por meio da construção de reservatórios de água de chuva que tem como fins a democratização e a gestão descentralizada dos recursos hídricos para atender as necessidades locais. Desse modo, as famílias residentes na zona rural passam de dependentes a gestoras de sua própria água.

A população rural da cidade de Cubati-PB, como já dito, é constituída por 2.097 pessoas (IBGE,2012). O município conta com três assentamentos rurais do Instituto Nacional de Colonização e Reforma Agrária (INCRA), assim denominados: Dorcelina Folador, São Domingos e Belo Monte e um quarto denominado Santa Ana organizado pelo Instituto de Terras e Reforma Agrária (ITERPE). De acordo com dados coletados, durante a pesquisa, no município existem 11 associações rurais, porém, apenas seis, são atuantes no Conselho Municipal de Desenvolvimento Rural e Sustentável (CMDRS). Os entrevistados 
se mostraram preocupados com a falta de engajamento das associações, uma vez que, muitos benefícios foram conquistados para o município através dessas organizações.

$\mathrm{O}$ acesso à água na zona rural do município acontece por diversas fontes como: açudes de pequeno porte, barreiros tradicionais, barreiros trincheira, barragens, cisternas, tanque de pedras, cacimbas, poços artesianos e vindas de outros municípios através dos carros pipas (operação carro pipa do exército, particular e da prefeitura).

A convivência com o Semiárido pressupõe a adoção da cultura do estoque de água para diversos usos, quais sejam: consumo humano, produção de alimentos para a família e para a criação animal. O primeiro programa desenvolvido pela ASA, no início dos anos 2000, foi o Programa Um Milhão de Cisternas (P1MC), com a perspectiva de melhorar a vida das famílias que vivem na Região Semiárida do Brasil, garantindo o acesso à água de qualidade (ASA, 2021).

Dentre as tecnologias sociais do P1MC implantada no município de Cubati - PB, temos como exemplo a cisterna localizada no sitio Praia Nova (Figura 2). Trata-se de uma cisterna de placas padrão, constituída fundamentalmente, por um reservatório cilíndrico com capacidade de armazenar 16 mil litros de água, o que permite suprir a necessidade de consumo de uma família de cinco pessoas por um período de estiagem de oito meses.

A cisterna é uma tecnologia popular para o aproveitamento da água da chuva, cuja água que escorre do telhado da casa é captada pelas calhas e cai diretamente na cisterna na qual é armazenada. Em todas as cisternas são instaladas bombas manuais para retirada da água, placas de identificação, calhas, tampas, coadores, telas de proteção e cadeados. Antes da construção das cisternas as famílias passam por um processo de capacitação para a gestão dessa nova atividade na casa, visto que a grande maioria das famílias não tem experiência com essa nova tecnologia.

Figura 2: Cisterna para captação de água de chuva no Sitio Praia Nova no município de Cubati-PB.

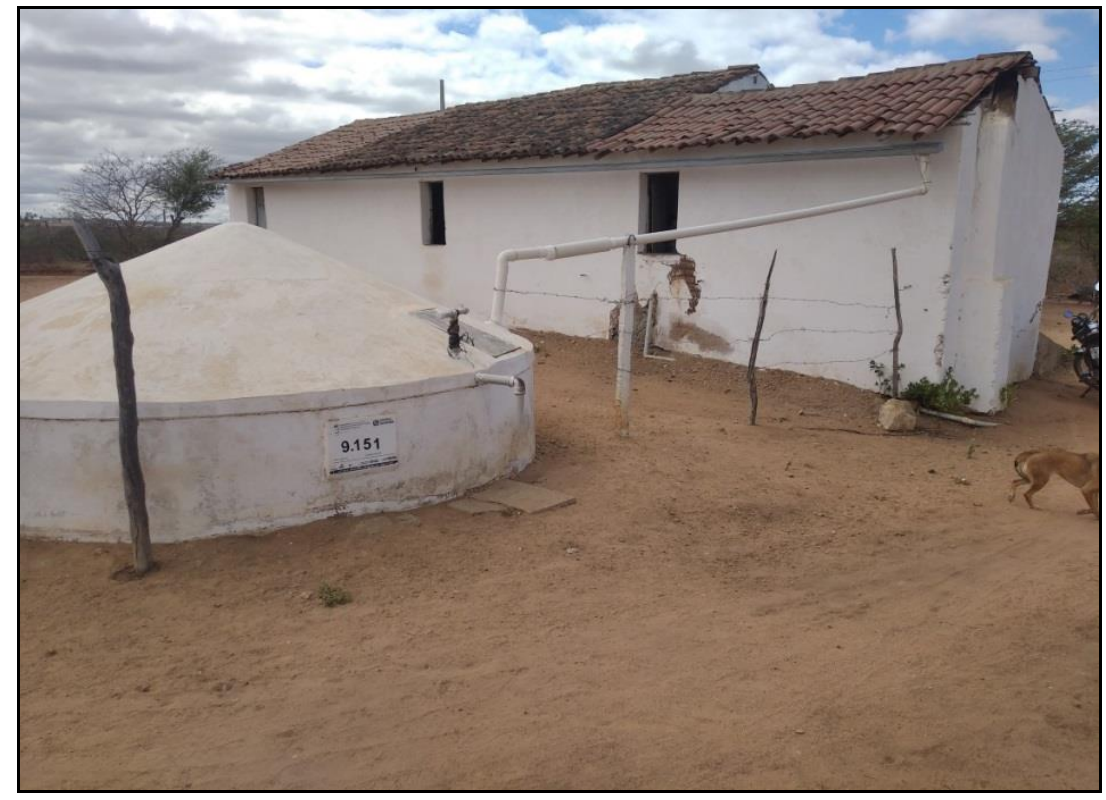

Fonte: Autoria própria (2021).

Com o objetivo de ampliar o estoque de água das famílias, comunidades rurais e populações tradicionais para dar conta das necessidades dos plantios e das criações animais, a ASA (Articulação Semiárido Brasileiro) criou em 2007 o Programa Uma Terra e Duas Águas, o P1+2. O nome do programa faz jus à estrutura mínima que as famílias precisam para produzirem o espaço para plantio e criação animal; a terra e a água para cultivar e manter a vida das plantas e dos animais. O P1+2 integra o Programa de Formação e Mobilização Social para a Convivência com o Semiárido, da ASA. Esse programa "guarda chuva" congrega também o Programa Um Milhão de Cisternas, o P1MC (ASA, 2021). 
As tecnologias que captam e guardam água da chuva para produção de alimentos são variadas e levam em consideração as características do local onde vão ser implementadas e a sua interação com a estratégia utilizada pela família para produzir. Atualmente, o P1+2 trabalha com sete tecnologias sociais, quais sejam: cisterna-calçadão, barragem subterrânea, tanque de pedra ou caldeirão, Bomba d'água popular, barreiro trincheira, barraginha e cisterna enxurrada.

Em visitas nas localidades rurais do município em estudo foi possível verificar, in loco, algumas implementações das tecnologias sociais do P1+2. No entanto, tendo em vista que o primeiro passo, antes da construção das tecnologias, é a participação das famílias em formações para a convivência com o Semiárido - as capacitações em Gerenciamento da Água para Produção de Alimentos (GAPA) e em Sistema Simplificado de Manejo da Água (SSMA) - foi possível verificar que as famílias ainda não se apropriaram dos princípios que foram explanados durante as capacitações (Figura 3), pois, ao serem questionados sobre as más condições em que se encontravam os reservatórios, os moradores justificaram o ocorrido relacionando ao fato da pouca incidência de chuvas nos últimos anos.

Figura 3: Tecnologias Sociais (cisterna calçadão, cisterna enxurrada e barreiro trincheira) implementadas pelo P1+2 no município de Cubati-PB.

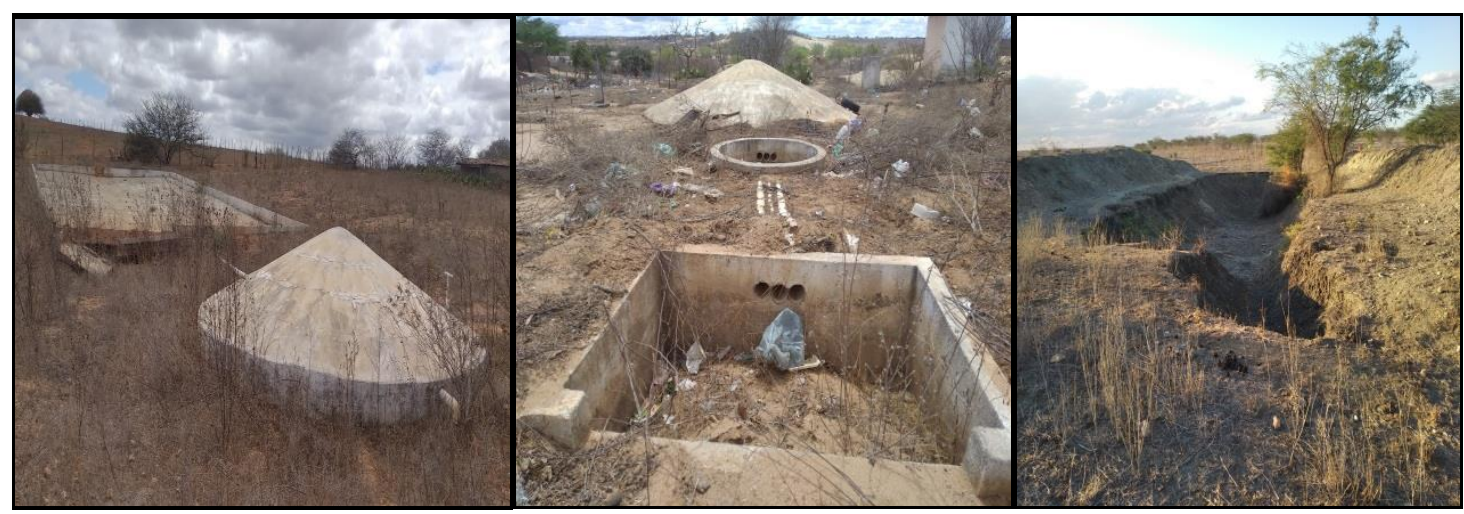

Fonte: Autoria própria (2021).

Assim, conhecendo a problemática que permeia o acesso à água na região semiárida do Brasil, em decorrência do longo período de estiagem, evaporação, poluição dos rios, e as águas salobras na maioria dos poços artesianos, o poder público procurou ampliar ações para garantir o atendimento da demanda de água de qualidade. Desse modo, consolidou parceria com os ministérios e diversas outras instituições federais, estaduais, municipais e da sociedade civil, e anunciou no ano de $2004 \mathrm{o}$ Programa Água Doce (PAD), o qual, tem como premissa básica, o compromisso do Governo Federal de garantir a população do Semiárido o aceso á água de boa qualidade.

O PAD busca estabelecer uma política pública permanente de acesso à água de boa qualidade para o consumo humano por meio do aproveitamento sustentável de águas subterrâneas, incorporando cuidados ambientais e sociais na gestão de sistemas de dessalinização. Na Paraíba, quem executa as ações do Programa é a Fundação de Apoio à Pesquisa do Estado da Paraíba (FAPESQ), através de equipe contratada e treinada, coordenada pela Secretaria de Infraestrutura, Recursos Hídricos e Meio Ambiente do Estado, atendendo convenio firmado em 2011 com o Ministério do Meio Ambiente (FAPESQ, 2019).

Dentre os municípios contemplados com os sistemas de dessalinização, está Cubati-PB. O sistema de dessalinização do município em estudo foi implantado na localidade São Domingos em maio de 2016 (Figura 4). Durante a visita, in loco, realizada em 2021 foi constatado que o mesmo continua bem preservado e em funcionamento, beneficiando 23 famílias do assentamento São Domingos e de outras localidades com água para consumo humano, além de dessedentação animal com a 
água salobra, que seria considerada "rejeito", resultante do processo de dessalinização. As famílias beneficiadas com a água contribuem mensalmente com um valor de $\mathrm{R} \$ 5,00$ para auxiliar na manutenção do sistema.

Figura 4: Sistema de dessalinização do PAD - na localidade São Domingo, Cubati-PB.

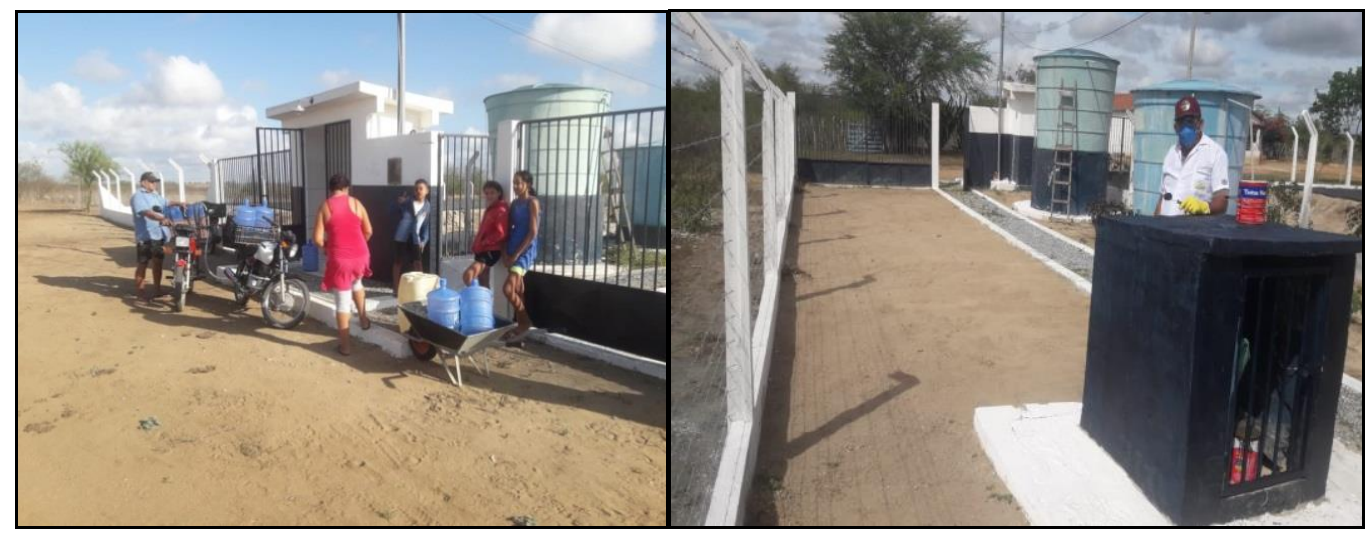

Fonte: Autoria própria (2021).

Dada a importância do sistema de dessalinização de águas salobras para o município de Cubati-PB foi constatado que a gestão pública municipal é atuante para manutenção e fiscalização do sistema, uma vez que, mantem um funcionário responsável no local para acompanhar, fazer a manutenção básica e manter o controle da distribuição da água para a população.

No assentamento São Domingos localizado no município de Cubati-PB, também foi implantada tecnologias de tratamento de esgoto na escala familiar para reuso agrícola, através do Instituto Nacional do Semiárido (INSA) e o sistema implantado é denominado de SARA (Sistema de Abastecimento e Reuso de Água). O funcionamento do sistema acontece da seguinte forma: todo esgoto coletado da casa vai para um tanque de equalização, sendo que o esgoto da cozinha passa antes por uma caixa de gordura e segue para o Reator UASB onde ocorre à remoção de materiais sólidos e orgânicos, seguindo para lagoas de polimento para a remoção de material patogênico. Como se trata de um tratamento anaeróbico não acontece à remoção dos nutrientes, desse modo a água é acumulada em um reservatório e distribuída para um sistema de irrigação de forragens e frutíferas.

Em visita ao sistema foi relatado pela família que, embora a água não seja suficiente para ter uma boa produção, é muito importante para manter as plantas vivas durante os períodos de estiagem. A família demonstrou satisfação com a implantação do sistema, explicou com muita clareza o funcionamento e relatou a importância do mesmo para atender aos princípios do desenvolvimento sustentável.

Em função do longo período de estiagem no município de Cubati-PB, a água que chega para abastecer a população rural por meio dos carros pipas são oriundos dos reservatórios locais e de outros municípios através da operação carro pipa, da gestão municipal e por particulares. Esta dependência sinaliza falha no sistema de gestão hídrica na zona rural.

\subsection{Cenários prospectivos de acesso à água na zona rural do município de Cubati-PB,}

$\mathrm{O}$ presente tópico remete aos resultados alcançados pela pesquisa tendo em vista atender o objetivo geral do estudo que é construir cenários prospectivos de acesso à água na zona rural do município de Cubati - PB, em um horizonte temporal de cinco anos (2022-2026). Os cenários construídos são classificados em cenários: mais provável, de tendência e ideal. 
Na pesquisa de campo foram levantadas questões endógenas e exógenas que impactam de forma positiva e negativa o sistema de acesso à água no recorte geográfico da pesquisa nos últimos 10 anos. Desse modo, foi possível listar de forma preliminar vinte eventos que podem ocorrer nos próximos cinco anos (Quadro 2).

Quadro 2: Eventos preliminares com potencial de impactar o sistema de acesso à água na zona rural do município de CubatiPB.

\begin{tabular}{|c|c|}
\hline EVENTO & DESCRIÇÃO \\
\hline 01 & Mudanças climáticas \\
\hline 02 & Índices pluviométricos \\
\hline 03 & Melhora na Gestão ambiental e hídrica local \\
\hline 04 & Enfraquecimento da Gestão ambiental e hídrica na esfera Federal \\
\hline 05 & Redução da renda da população \\
\hline 06 & Agricultura de irrigação insustentável \\
\hline 07 & Fortalecimento da atuação das associações rurais \\
\hline 08 & Redução na elaboração e implementação de políticas públicas de acesso à água. \\
\hline 09 & Realização de construção e manutenção dos reservatórios de água pela gestão municipal \\
\hline 10 & Redução das Injustiças na distribuição dos benefícios e da água nas comunidades rurais \\
\hline 11 & Aumento da Contaminação dos reservatórios hídricos e do solo \\
\hline 12 & Redução nos incentivos financeiros direcionados aos agricultores \\
\hline 13 & $\begin{array}{l}\text { Ausência de educação ambiental formal e informal para sensibilização e conscientização da } \\
\text { população sobre a temática ambiental. }\end{array}$ \\
\hline 14 & Negligência nas medidas sanitárias de manejo e acondicionamento de água. \\
\hline 15 & Ausência da apropriação do princípio de gestão compartilhada e descentralizada da população \\
\hline 16 & $\begin{array}{l}\text { Falta de sensibilização da população para manter preservada as tecnologias sociais hídricas do } \\
\qquad \mathrm{P} 1 \mathrm{MC} \text { e } \mathrm{P} 1+2\end{array}$ \\
\hline 17 & Aumento da desertificação \\
\hline 18 & Redução dos recursos naturais disponíveis \\
\hline 19 & Melhorias na forma de planejamento municipal para atender a demanda hídrica rural \\
\hline 20 & $\begin{array}{c}\text { Redução na elaboração e implementação de politicas públicas voltadas para a Convivência com o } \\
\text { Semiárido. }\end{array}$ \\
\hline
\end{tabular}

Fonte: Autoria própria (2020).

$\mathrm{Na}$ sequência, foram selecionados oito peritos (conhecedores da situação hídrica do município), os quais foram convidados a responderem um questionário do Google Forms com os vinte eventos identificados na primeira etapa da pesquisa para que eles selecionassem 10 como sendo definitivos, ou seja, aqueles mais prováveis de impactar o sistema de acesso à água nos próximos cinco anos. Para responder ao questionário os peritos foram orientados a seguir os seguintes critérios: eventos que apresentassem probabilidade $\geq 60 \%$ (muito provável de ocorrer nos próximos 5 anos) e pertinência $\geq 70 \%$ (alta em relação ao objeto de estudo). Desse modo, forram selecionados os 10 eventos definitivos (Quadro 3). 
Quadro 3: Eventos Definitivos.

\begin{tabular}{|c|c|}
\hline EVENTOS & DESCRIÇÃO \\
\hline 01 & Mudanças climáticas \\
\hline 03 & Melhorias na gestão ambiental e hídrica local \\
\hline 04 & Enfraquecimento da Gestão ambiental e hídrica na esfera Federal \\
\hline 05 & Redução da renda da população \\
\hline 06 & Ausência de Educação Ambiental formal e informal para conscientização da \\
população sobre a temática ambiental.
\end{tabular}

Fonte: Autoria própria (2020).

Após o consenso dos dez eventos definitivos, foi realizada a segunda consulta aos peritos, para o preenchimento da matriz de impactos cruzados para avaliar a capacidade de cada evento influenciar os demais e de ser influenciados (Marcial \& Grumbach, 2006).

A Matriz de Impactos Cruzados é formada pela intersecção de colunas e linhas. Os números correspondentes aos dez eventos preenchem as linhas e as colunas, de modo que os dez eventos estejam presentes nas linhas e colunas que fazem o cruzamento. A probabilidade de ocorrência dos eventos também está presente na matriz. Os peritos preencheram os espaços vazios de intersecção os quais serão utilizados para calcular a motricidade e dependência dos eventos (Quadro 4).

Quadro 4: Matriz de Impactos Cruzados (motricidade e dependência).

\begin{tabular}{|c|c|c|c|c|c|c|c|c|c|c|c|c|}
\hline Eventos & Prob. & $\mathbf{0 1}$ & $\mathbf{0 3}$ & $\mathbf{0 4}$ & $\mathbf{0 5}$ & $\mathbf{0 6}$ & $\mathbf{1 3}$ & $\mathbf{1 5}$ & $\mathbf{1 7}$ & $\mathbf{1 8}$ & $\mathbf{2 0}$ & Dep. \\
\hline $\mathbf{0 1}$ & 8,0 & & 2 & 4 & 2 & 4 & 7 & 6 & 8 & 6 & 8 & 4,7 \\
\hline $\mathbf{0 3}$ & 6,0 & 1 & & 7 & 3 & 2 & 6 & 4 & 1 & 2 & 7 & 3,3 \\
\hline $\mathbf{0 4}$ & 4,0 & 1 & 1 & & 1 & 2 & 3 & 3 & 1 & 2 & 1 & 1,5 \\
\hline $\mathbf{0 5}$ & 4,0 & 3 & 2 & 4 & & 5 & 3 & 2 & 4 & 4 & 8 & 3,5 \\
\hline $\mathbf{0 6}$ & 7,0 & 4 & 1 & 3 & 2 & & 2 & 2 & 5 & 6 & 3 & 2,8 \\
\hline $\mathbf{1 3}$ & 6,0 & 1 & 2 & 1 & 3 & 2 & & 1 & 2 & 1 & 5 & 1,8 \\
\hline $\mathbf{1 5}$ & 8,0 & 2 & 6 & 6 & 2 & 3 & 7 & & 2 & 1 & 8 & 3,7 \\
\hline $\mathbf{1 7}$ & 6,0 & 7 & 2 & 5 & 2 & 4 & 6 & 3 & & 5 & 6 & 4,0 \\
\hline $\mathbf{1 8}$ & 6,0 & 5 & 1 & 7 & 2 & 6 & 7 & 4 & 7 & & 8 & 4,7 \\
\hline $\mathbf{2 0}$ & 8,0 & 1 & 2 & 8 & 2 & 2 & 3 & 4 & 2 & 1 & & 2,5 \\
\hline Motricidade & & 2,5 & 1,9 & 4,5 & 1,9 & 3,0 & 4,4 & 2,9 & 3,2 & 2,8 & 5,2 & \\
\hline
\end{tabular}

Fonte: Elaborada pela autora com base em dados coletados (2021).

Com base nos resultados obtidos por meio da elaboração da Matriz de Impactos Cruzados Medianos, foi possível 
identificar o grau de motricidade e dependência dos eventos, elaborando um gráfico de Motricidade versus Dependência. O plano de motricidade e dependência é de suma importância, visto que, será feito a divisão dos dez em quatro quadrantes. De acordo com cada quadrante que os eventos os ocuparem serão classificadas em: explicativos, de ligação, autônomos e de resultados (Figura 5).

Figura 5: Plano de Motricidade e dependência.

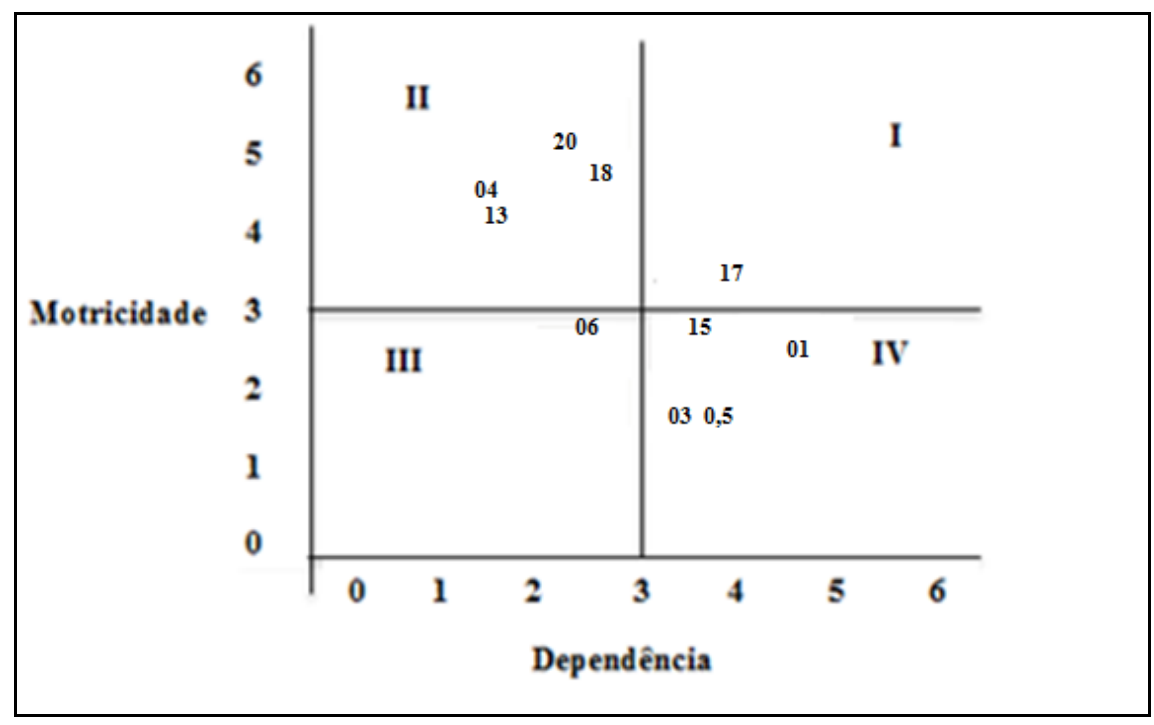

Fonte: Elaborado pela autora com base em dados coletados.

No quadrante I (motricidade e dependência) se encontra o evento 17 (aumento da desertificação). O respectivo evento tanto pode ser alterado, como também é capaz de influenciar outros, se sofrer algumas ações. Desse modo, é considerado de ligação, pois, apresenta elevado grau de motricidade e de dependência.

O quadrante II corresponde aos eventos que possuem grande capacidade de influenciar os demais, mas são poucos influenciados. De acordo com Marcial e Grumbach (2008), são explicativos, pois possuem grande motricidade e pouca dependência. São aqueles que condicionam o funcionamento do sistema. Os eventos do quadrante II são: 04 - enfraquecimento da gestão ambiental e hídrica na esfera federal; 13 - Ausência de educação ambiental formal e informal para conscientização da população sobre a temática ambiental; 18 - Redução dos recursos naturais disponíveis e o evento 20 - redução na elaboração e implementação de políticas públicas voltadas para a Convivência com o Semiárido. Esses quatro eventos impactam o sistema de acesso à água.

A evento 06 - Agricultura de irrigação, que se encontra no quadrante III apresenta baixo nível de motricidade e de dependência, são considerados "autônomos".

No quadrante IV encontram-se os eventos de "resultados" por apresentarem uma baixa motricidade e elevado nível dependência dos demais. Os eventos de resultados são: 01- mudanças climáticas; 03 - melhorias na gestão ambiental e hídrica local; 05 - reduções da renda da população e 15 - ausências da apropriação do princípio da gestão compartilhada e descentralizada da população.

Após a elaboração do plano de motricidade e dependência, os peritos foram novamente convidados a opinarem sobre a probabilidade de ocorrência ou não ocorrência dos eventos considerados como definitivos para impactar o sistema nos próximos 5 anos. Os cenários construídos foram classificados em: provável, de tendência e ideal conforme expostos no Quadro 5. 
De acordo com Marcial e Grumbach (2008), o cenário mais provável é o que tem maior probabilidade de ocorrência no horizonte temporal considerado; o cenário ideal é aquele em que ocorrem os eventos favoráveis e não ocorrem os desfavoráveis; e o cenário de tendência é aquele que apresenta chances de acontecer se o curso dos eventos se mantiver como no momento presente. Esse cenário leva em consideração a possibilidade de ocorrerem rupturas, isto é, de surgirem fatos que importam ao objeto de estudo e que, em consequência, possam interferir nos eventos futuros.

Quadro 5: Cenários: Provável, Tendência e Ideal.

\begin{tabular}{|c|c|c|c|}
\hline Eventos & Provável & Tendência & Ideal \\
\hline 01: mudanças climáticas & $\mathbf{O}$ & $\mathbf{O}$ & $\mathbf{N}$ \\
\hline 03: Melhorias na gestão ambiental e hídrica local & $\mathbf{O}$ & $\mathbf{O}$ & $\mathbf{O}$ \\
\hline 04: Enfraquecimento da Gestão ambiental e hídrica na esfera Federal & $\mathbf{O}$ & $\mathbf{O}$ & $\mathbf{N}$ \\
\hline 05: Redução da renda da população & $\mathbf{O}$ & $\mathbf{O}$ & $\mathbf{N}$ \\
\hline 06: Agricultura de irrigação insustentável & $\mathbf{O}$ & $\mathbf{O}$ & $\mathbf{N}$ \\
\hline $\begin{array}{c}\text { 13: Ausência de Educação Ambiental formal e informal para } \\
\text { conscientização da população sobre a temática ambiental. }\end{array}$ & $\mathbf{O}$ & $\mathbf{O}$ & $\mathbf{N}$ \\
\hline $\begin{array}{c}\text { 15: Ineficiência da apropriação do principio da gestão compartilhada e } \\
\text { descentralizada da população }\end{array}$ & $\mathbf{O}$ & $\mathbf{O}$ & $\mathbf{N}$ \\
\hline 17: Aumento da desertificação & $\mathbf{O}$ & $\mathbf{O}$ & $\mathbf{N}$ \\
\hline 18: Redução dos recursos naturais disponíveis & & $\mathbf{O}$ & $\mathbf{N}$ \\
\hline 20: Redução na elaboração e implementação de Politicas Públicas \\
voltadas para a Convivência com o Semiárido.
\end{tabular}

Fonte: Autoria própria (2021).

\subsection{Interpretações dos cenários}

A interpretação de cenários é possível ser realizada de diversas formas na metodologia proposta por Marcial e Grumbach (2008). Para tanto, a sugestão é que os cenários sejam classificados em "mais provável”, "de tendência" e "ideal.

\section{A. Cenário mais provável}

Para Marcial e Grumbach (2008), o cenário mais provável é o que aparece no topo das relações de cenários. Os analistas devem realizar a correlação lógica dos eventos sempre com base nas pesquisas feitas anteriormente, para, dessa forma, criar o caminho que leva ao final do horizonte temporal estabelecido. Depois de realizado o encadeamento lógico dos acontecimentos, o analista deve procurar no cenário alguns acontecimentos, tais como: acontecimentos desfavoráveis dentro do objeto de estudo, acontecimentos desfavoráveis fora do objeto de estudo e acontecimentos favoráveis ao objeto de estudo.

Acontecimentos desfavoráveis dentro do objeto de estudo - é a ocorrência dos eventos desfavoráveis ao estudo de cenários que viabilizem o acesso à água na zona rural do município de Cubati-PB, também pela não ocorrência dos eventos favoráveis. Nesses eventos, as ações realizadas no presente podem alterar a ocorrência deles no futuro. Dentro do objeto de estudo em analise os eventos desfavoráveis são: 04 - Enfraquecimento da gestão ambiental e hídrica na esfera Federal; 05 Redução da renda da população; 06 - Agricultura de irrigação insustentável; 13 - Ausência de educação ambiental formal e informal para conscientização da população sobre a temática ambiental; 15 - Ineficiência da apropriação do princípio da corresponsabilidade para promover o acesso à água; 20 - Redução na elaboração e implementação de políticas públicas voltadas para a Convivência com o Semiárido. 
Os acontecimentos desfavoráveis fora do recorte do objeto de estudo são construídos pela ocorrência de eventos desfavoráveis e a não ocorrência de eventos favoráveis ao objeto de estudo, não sendo possível a alteração das probabilidades de ocorrência dos eventos, quais sejam: 01 - mudanças climáticas; 17 - Aumento da desertificação e 18 - Redução dos recursos naturais disponíveis.

Os acontecimentos favoráveis ao objeto de estudo caracterizam-se pela ocorrência de eventos favoráveis e pela não ocorrência dos eventos desfavoráveis ao objeto de estudo. Nesse caso, devem-se articular ações no presente, tirar melhor proveito dos acontecimentos futuros que lhe são favoráveis. No presente estudo apenas um evento favorável ao objeto deste estudo foi mencionado pelos peritos que foram as melhorias na gestão ambiental e hídrica local.

\section{B. Cenário de tendência}

Para Marcial e Grumbach (2008), cenário de tendência é aquele que provavelmente ocorrerá se o curso dos acontecimentos se mantiver como no momento presente. Esse cenário leva em consideração a possibilidade de ocorrerem rupturas, ou seja, o surgimento de fatos que importam ao objeto de estudo e, em consequência, possam interferir nos eventos futuros. No estudo em análise, não foi diagnosticado nenhuma ruptura, motivo pelo qual não foi descrito o cenário de tendência, pois o respectivo cenário compactua com os mesmos eventos do cenário provável, os quais já foram expostos.

\section{Cenário ideal}

O cenário ideal de acordo com Marcial e Grumbach (2008) é aquele em que ocorrem os eventos favoráveis e não ocorrem os desfavoráveis. O cenário ideal do estudo fica estruturado mediante a ocorrência da variável: 03 - Melhorias na gestão ambiental e hídrica local e a não ocorrência das variáveis: 01 - mudanças climáticas; 04 - Enfraquecimento da Gestão ambiental e hídrica na esfera Federal; 05 - Redução da renda da população; 06 - Agricultura de irrigação insustentável; 13 Ausência de educação ambiental formal e informal para conscientização da população sobre a temática ambiental; 15 Ineficiência da apropriação do princípio da gestão compartilhada e descentralizada da população; 17 - Aumento da desertificação; 18 - Redução dos recursos naturais disponíveis; 20 - Redução na elaboração e implementação de políticas públicas voltadas para a Convivência com o Semiárido. Desse modo, o estudo não identifica a ocorrência de um cenário ideal de acesso à água para os próximos cinco anos, justificando-se pela quantidade de variáveis desfavoráveis (nove) entre as dez consideradas como definitivas.

\section{Considerações Finais}

O estudo possibilitou sistematizar a cenarização prospectiva do acesso à água na zona rural do município de CubatiPB, Seridó Oriental Paraibano, para os próximos cinco anos, a partir da aplicação parcial da metodologia de cenário idealizada por Grumbach. Desse modo, buscou-se o futuro no presente, avaliando experiências passadas. Essas "memórias do futuro" viabilizam o conhecimento de variáveis desfavoráveis ao acesso à água na região Semiárida, na tentativa de despertar a sociedade civil e os gestores a implementar ações proativas ao invés das reativas na perspectiva de minimizar o agravamento do sistema de gestão hídrica.

Evidenciam-se que os cenários prospectivos de acesso à água no município de Cubati-PB, para os próximos cinco anos (mais provável, de tendência e ideal) sinalizam para um elemento implicador, ou seja, a quantidade de eventos desfavoráveis aos sistemas é superior (nove) aos favoráveis (um).

O estudo também evidencia que os eventos impactantes no acesso à água estão inseridos no âmbito do cenário ambiental global como (mudanças climáticas, redução dos recursos naturais disponíveis e aumento da desertificação); nacional (Enfraquecimento da Gestão ambiental e hídrica na esfera Federal, redução da renda da população, redução da elaboração e 
implementação de Políticas Públicas voltadas para a Convivência com o Semiárido, melhorias na gestão ambiental e hídrica local, ausência de educação ambiental formal e informal para conscientização da população sobre a problemática ambiental, além da ausência de uma gestão compartilhada com a participação da sociedade civil e movimentos sociais.

Destarte, o acesso à água de forma mais justa e democrática na região semiáridas brasileira precisa implementar uma melhor gestão e controle do uso das águas na região, o que não aconteceu durante a maior parte da história das políticas hídricas na região. Demanda ainda, planejamentos fundamentados na cenarização prospectiva, uma vez que, constitui a oportunidade de conhecer, além das variáveis globais e nacionais, as locais, através da participação de diversos atores sociais que externam as peculiaridades inerentes a sua realidade. Essa perspectiva vai ao encontro dos princípios do novo paradigma que vem sendo implementado para a elaboração e implementação das políticas públicas de convivência com o Semiárido nas últimas décadas.

Em suma, recomenda-se a replicação desse estudo em outros municípios, uma vez que, apresenta potencial de promover informações oriundas da percepção dos atores sociais locais, as quais, serviram de base para o planejamento da elaboração e implementação de políticas públicas caracterizadas.

\section{Referências}

ASA. (2021). Articulação Semiárido Brasileiro.

ANA. Agência Nacional de Águas (Brasil). (2015) Conjuntura dos recursos hídricos do Brasil: Regiões hidrográficas brasileiras. ANA.

Assis, T. R. P. (2012). Sociedade Civil e a Construção de Politicas Públicas na Região: o caso do Programa Um Milhão de Cisternas Rurais (P1MC). Revista Política Pública, 1 (16), 179-189.

Baptista, N. Q. \& Campos, C. H. (2013). A Convivência com o Semiárido e suas potencialidades. In: Conti, I. L. Schroeder, E. O. (Org). Convivência com o Semiárido Brasileiro Autonomia e Protagonismo Social.: IABS, p. 51-58.

Brasil. (2005). Ministério da Integração Nacional. Portaria nº 89, de 16 de março de 2005.

Boff, L. (2010). Proteger a terra-cuidar da vida: como escapar do fim do mundo.: Record.

Buriti, C. O. \& Barbosa, H. A. (2019). Secas e Vulnerabilidade Socioambiental no Semiárido Brasileiro: a institucionalização dos Estudos Científicos e das Políticas Hídricas na Região. Revista: Ciência Geográfica. 23 (23), 267-282.

Conti, I. L. \& Pontel, E. (2013). Transição Paradigmática na Convivência Com o Semiárido. In: Conti, I. L. \& Schroeder, E. O. (Org). Convivência com o Semiárido Brasileiro Autonomia e Protagonismo Social. Brasília: IABS, p. 21-30.

Fapesq - Fundação de Apoio à Pesquisa do Estado da Paraíba (2019). Programa Água Doce beneficia 30 mil pessoas na Paraíba. http://fapesq.rpp.br/noticias/programa-agua-doce-beneficia-30-mil-pessoas-na-paraiba

Godet, M. (2000). A Caixa de Ferramentas da Prospectiva Estratégica. CEPES.

IBGE. Instituto Brasileiro de Geografia e Estatística. (2010). Estimativa Estatística 2010.

IBGE. Instituto Brasileiro de Geografia e Estatística. (2012). Produto Interno Bruto dos Municípios 2012.

Lessa, N. O.; Belderrain, M. C. N. \& Marchi, M. M (2006). Proposta de metodologia de construção de cenários prospectivos para apoio ao planejamento estratégico militar. In: Anais do Simpósio de Pesquisa Operacional e Logística da Marinha (SPOLM). Rio de Janeiro, $773-787$.

Marcial, E. C. \& Grumbach, R. J. S. (2006). Cenários Prospectivos: como construir um futuro melhor. (4a ed.), Rio FGV.

Marcial, E. C. \& Grumbach, R. J. S. (2008). Cenários Prospectivos: como construir um futuro melhor. (5a ed.), FGV.

Marcial, E. L. \& Costa, A. J. L. (2001). O uso de cenários prospectivos na estratégia empresarial: vidência especulativa ou Inteligência Competitiva? In: Anais Encontro Nacional de Pesquisa em Administração, 25, 2001. Campinas: ENANPAD.

Porter, M. (1989). Vantagem competitiva: criando e sustentando um desempenho superior. (16a ed.), Campus.

Passador, C. S, Passador, L. J. \& Huayta, V. R. (2010). Políticas Contra la Sequía e la Técnica de Cisterna en Brasil. Revista Agroalimentaria, $16,101-113$.

Silva, R. A. M. (2003). Entre Dois Paradigmas: combate à Seca e Convivência com o Semiárido. Revista Sociedade e Estado. 181 (1/2), 361-385.

Silva, R. A. M. (2006). Entre o combate à seca e a convivência com o Semiárido: transições paradigmáticas e sustentabilidade do desenvolvimento. (Tese de Doutorado em Desenvolvimento Sustentável), Universidade de Brasília, Brasília. 
Research, Society and Development, v. 11, n. 3, e16011326274, 2022

(CC BY 4.0) | ISSN 2525-3409 | DOI: http://dx.doi.org/10.33448/rsd-v11i3.26274

Silva, J. E. A. (2012). Cenários Prospectivos Em Redes de Cooperação: O caso da associação de produtores rurais dos campos de cima da serra APROCCIMA. Caxias do Sul - RS. (Dissertação de Mestrado em Administração), Universidade de Caxias do Sul, Caxias do Sul.

Schwartz, P. (2006). A arte da visão de longo prazo: planejando o futuro em um mundo de incertezas.: Best Seller. 